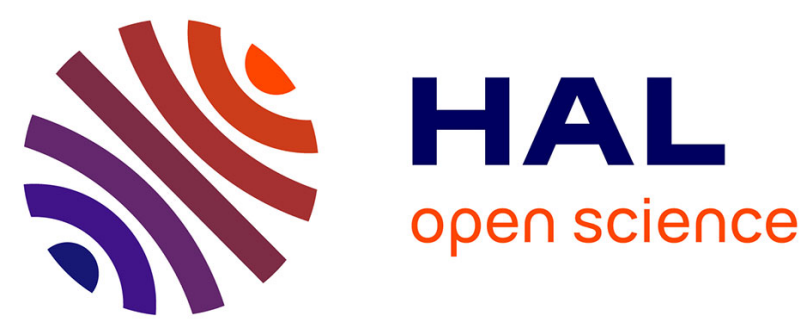

\title{
THE EFFECTS OF METALLIC INTERLAYER FORMATION ON THE ADHESION PROPERTIES OF PACVD - TiN FILMS ON TOOL STEEL
}

\author{
S. Kim, C. In, S. K. Choi, S. Chun
}

\section{> To cite this version:}

S. Kim, C. In, S. K. Choi, S. Chun. THE EFFECTS OF METALLIC INTERLAYER FORMATION ON THE ADHESION PROPERTIES OF PACVD - TiN FILMS ON TOOL STEEL. Journal de Physique IV Proceedings, 1991, 02 (C2), pp.C2-609-C2-616. 10.1051/jp4:1991273 . jpa-00249863

HAL Id: jpa-00249863

https://hal.science/jpa-00249863

Submitted on 1 Jan 1991

HAL is a multi-disciplinary open access archive for the deposit and dissemination of scientific research documents, whether they are published or not. The documents may come from teaching and research institutions in France or abroad, or from public or private research centers.
L'archive ouverte pluridisciplinaire HAL, est destinée au dépôt et à la diffusion de documents scientifiques de niveau recherche, publiés ou non, émanant des établissements d'enseignement et de recherche français ou étrangers, des laboratoires publics ou privés. 
Colloque C2, suppl, au Journal de Physique II, Vol. 1, septembre 1991

\title{
THE EFFECTS OF METALLIC INTERLAYER FORMATION ON THE ADHESION PROPERTIES OF PACVD - TIN FILMS ON TOOL STEEL
}

\author{
S.B. KIM, C.B. IN, S.K. CHOI and S.S. CHUN \\ Department of Materials Science and Engineering, Korea \\ Advanced Institute of Science and Technology, P.0. Box 150, \\ Cheongryang, Seoul, Korea
}

\begin{abstract}
The adhesion of PACVD - TiN films on tool steel ( AISI MD) has been investigated as a function of interfacial chemistry and the metallic interlayer formation between TiN films and substrate steel. Prior to TiN deposition, thin metallic interlayers such as $\mathrm{Ti}, \mathrm{Cr}, \mathrm{Cu}$ films were deposited on a steel substrate with thickness range of $200-2000 \AA$ by Magnetron sputtering. TiN films were deposited by RF Glow Discharge PACVD technique using the gaseous mixture of TiC14, $\mathrm{N} 2, \mathrm{H} 2$ and $\mathrm{Ar}$ at $520^{\circ} \mathrm{C}$. The adhesion strength of TiN films was investigated by Scratch Adhesion Tester ( REVETEST model ) with a diamond stylus. The critical load in adhesion test was about $35 \mathrm{~N}$ in the case of no metallic interlayer and it was increased up to $60 \mathrm{~N}$ in the presence of $200 \AA \mathrm{A}$ thick $\mathrm{Ti}$ interlayer. The interfacial composition profile was investigated by Auger depth profile. The experimental results indicated that a thin $\mathrm{Ti}$ intermediate layer $(<600 \AA)$ could increase the adhesion and the critical normal force in the scratch adhesion test was up to $60 \mathrm{~N}$. In the case of $\mathrm{Ti}$ interlayer formation, the oxygen in the interfacial region plays an important role on the adhesion of $\mathrm{TiN}$ coating by the formation of a $\mathrm{Ti}(\mathrm{ON})$ type phase.
\end{abstract}

\section{Introduction}

Titanium Nitride ( TiN ) has been widely used as a wear resistant coating material due to its high hardness, chemical inertness, and low friction coefficient. Nowadays the TiN coated steel tools prepared by various PVD ( Physical Vapor Deposition) methods are commercially available. In many industrial PVD - TiN processes, the deposition of a $\mathrm{Ti}$ intermediate layer has been used in order to ensure good adherence between coatings and the substrate. Several authors have investigated the influence of such a $\mathbf{T i}$ interlayer on the adhesion properties of the TiN coatings. Helmersson et al./1/ reported the formation of a $\mathrm{T}$ interlayer of $0.1 \mu \mathrm{m}$ thickness was beneficial for DC magnetron sputtered TiN coatings. Similar to this work, Stappen et al. $/ 2 /$ showed a positive effect of a $0.1-0.2 \mu \mathrm{m}$ thick Ti layer on the adhesion of ARE - TiN coatings. However, contrary to these works, Valli et al./3/ measured no increase in adhesion for ARE - TiN coatings with a $0.3 \mu \mathrm{m}$ Ti interlayer. From these works, it is suggested that an optimum thickness should be determined for such layers. 
An alternative to the current deposition techniques is Plasma Assisted CVD ( PACVD ) which can combine good film uniformity with lower deposition temperature. Recently TiN films prepared by this technique as a protective coating have been under increased investigation. For example, Li Shizhi et al./4/ reported that the application of PACVD - TiN and $\mathrm{Ti}(\mathrm{CN})$ in coating a range of steel tools with their pilot production scale PACVD apparatus gave a hard coating and concluded that PACVD could combine the advantages of PVD ( e.g. low process temperature ) and CVD ( e.g. good throwing power ). However in the PACVD - TiN coating process, no attempts have been made to deposit a interlayer in order to increase the adhesion of TiN coatings. Therefore in this study, prior to TiN deposition by PACVD, thin metallic interlayers such as $\mathrm{Ti}, \mathrm{Cr}, \mathrm{Cu}$ films were deposited on tool steel substrates in order to investigate the effects of such interlayers on the adhesion properties of PACVD - TiN and to find the optimum interlayer thickness. In addition, the relation between the adhesion properties and the interfacial chemistry is discussed.

\section{Experimental Details}

The M2 steel used as a base material was heat treated according to standard conditions and the measured hardness was $63 \pm 1 \mathrm{H}_{\mathrm{R}} \mathrm{C}$. Prior to TiN deposition, the substrates were sputter cleaned in an Ar atmosphere using an R.F. power ( 50 Watt) induced negative bias during $15 \mathrm{~min}$ and the thin metallic interlayers such as $\mathrm{Ti}, \mathrm{Cr}, \mathrm{Cu}$ films (of different affinity to oxygen ) were deposited on steel substrate with thicknesses in the range of 200 $2000 \AA$ by D.C. Magnetron Sputtering. The resulting specimens were charged in the PACVD reaction chamber for TiN coating. The TiN coatings were prepared by the R.F. Glow Discharge PACVD technique using a gaseous mixture of $\mathrm{TiCl}_{4}, \mathrm{~N}_{2}, \mathrm{H}_{2}$ and Ar. The experimental apparatus and deposition procedure used were as in previous paper $/ 5,6 /$ and the deposition conditions were as follows : deposition temperature, $520{ }^{\circ} \mathrm{C} ; \quad \mathrm{TiCl}_{4} / \mathrm{N}_{2} / \mathrm{H}_{2} / \mathrm{Ar}=$ 1/20/35/45; system pressure, 3 torr; R.F.power, 30 Watt; total flow rate, $200 \mathrm{sccm}$; deposition time, $2 \mathrm{hr}$. The resultant coating thickness was about $2 \mu \mathrm{m}$.

The scratch adhesion tester ( CSEM model) was used in order to evaluate the adhesion strength of the TiN coatings. The test condition was as follows : Diamond indenter tip radius, $0.2 \mathrm{~mm}$; loading rate, $100 \mathrm{~N} / \mathrm{min}$; sliding speed, $1 \mathrm{~cm} / \mathrm{min}$. In the adhesion test, it was found that two distinct transition points were observed along the scratches. One ( lower normal force ) corresponded to the onset of cracking and a little chipping around the indenter tip. However, over this region, the TiN coating layer still remained and was just deformed plastically. Fig. 1 shows such typical behavior in the scratch adhesion test. The other ( higher normal force) was associated with coating penetration and full detachment of the coating. In this study the higher value was considered as the critical normal force and it was used as a measure of TiN coating adhesion strength.

The analysis of the elemental distribution across the interface between the substrate and TiN coatings was carried out with scanning Auger microprobe ( SAM ) applying $5 \mathrm{keV} \mathrm{Ar}$. ion depth profiling. Auger line scan was detected with a $5 \mathrm{KeV}$ primary electron beam. The position and line shape of the positive excursion of the $\mathrm{Ti} \mathrm{L}_{3} \mathrm{M}_{23} \mathrm{M}_{45}$ peak at $418 \mathrm{eV}$ was monitored during the depth profiling in order to study the Auger fine structure of the TiN coatings because that is influenced by a $\mathrm{Ti}-\mathrm{N}$ cross transition at $413 \mathrm{eV}$ and the binding state.

The X-ray diffraction analysis was performed using the $\mathrm{Cu} \mathrm{K} \alpha$ radiation operated at a 
tube voltage of $30 \mathrm{kV}$ and a current of $40 \mathrm{~mA}$.

\section{Experimental Results and Discussion}

\section{A. Characteristics of PACVD - TiN}

The identification of the deposited layer was accomplished by the Auger electron spectroscopy ( AES ) and X-ray diffraction analysis. Representative AES spectra are shown in Fig. 2. Fig. 2 (a) was for an as received specimen and showed carbon and oxygen contamination at the surface, which occurred during the transport of a sample from the PACVD chamber to the AES chamber. After 10 min sputter etching with the Ar ion beam, the spectrum obtained is represented in Fig. 2 (b). The composition of the TiN layer was just analysed semi-quantitatively according to the Dawson and Tzatzov's method/7/, i.e., using the ratio of the peak height of $\mathrm{Ti}+\mathrm{N}$ peak $(383 \mathrm{eV})$ and $\mathrm{Ti}$ peak $(418 \mathrm{eV})$. From this, it was found that the deposited TiN layer was slightly $\mathrm{N}$ rich stoichiometrically and contained a small amount of chlorine $(-3 \%)$.

A typical X-ray diffraction result of the TiN layer is shown in Fig.3. It shows several peaks from the substrate ( originating from the Fe matrix and several types of carbide) due to the penetration depth of the X-ray. The TiN layer shows a distinct diffraction peak of the (200) crystallographic plane.

From the above experimental results, it can be seen that the PACVD - TiN coating layer in this study was a slightly overstoichiometric with respect to $\mathrm{N}$ and had a small amount of $\mathrm{Cl}$ with a strongly preferred orientation of (200). In addition, adhesion test results indicated that the critical normal force was within the range of $30-35 \mathrm{~N}$ in the case of no-interlayer under the TiN coatings.

\section{B. Effects of the metallic interlayer formation on the adhesion property of PACVD -} TiN coatings

The effects of the metallic interlayer formation on the critical normal force in the scratch adhesion test are shown in Fig. 4. A TiN coating with a Ti interlayer of less than $600 \AA$ thickness exhibited a improved adhesion compared to no-interlayer TiN coating. However, an increase in the Ti layer thickness gave a detrimental effect on the adhesion. In the case of a $\mathrm{Cr}$ interlayer, the adhesion was rather better than no-interlayer TiN coatings. However, when the $\mathrm{Cr}$ layer thickness was $1200 \AA$ and $2000 \AA$, the adhesion deteriorated so much that TiN coatings could be easily detached by Scotch tape test. It is seen from Fig. 4 that $\mathrm{Cu}$ interlayer formation was detrimental to the adhesion of TiN coatings to $\mathrm{M} 2$ steel substrate regardless of its thickness. This could be explained by the large difference in the thermal expansion coefficient $/ 8 /$ of $\mathrm{Cu}$ in comparison with TiN and steel. In addition, the decrease in the adhesion with the $\mathrm{Ti}$ and $\mathrm{Cr}$ layer thickness may be due to the fact that a relatively weak metallic interlayer could have remained after TiN deposition.

The variation of the interfacial elemental distribution as a function of metallic interlayer formation was examined by the Auger depth profile analysis and is represented in Fig. 5. The results obtained were for the case of $200 \AA$ thick interlayer formation. From Fig.5, it can be deduced by the elemental distribution in the interfacial region that the deposited metallic interlayer should exist in the form of compound after the TiN deposition. This compound formation would influence the adhesion of TiN coatings to the M2 steel substrate. 
The most significant features in the AES analysis were the variation of the oxygen content in the interfacial region, which could be considered to originate from the reactant gases ( the purity of the gases was $99.995 \%$ ), although each sample was prepared at the same time. These results might be due to the different oxygen affinities of $\mathrm{Ti}, \mathrm{Cr}, \mathrm{Cu}$. From the thermodynamic point of view i.e., Gibb's free energy of formation of the $\mathrm{Ti}, \mathrm{Cr}, \mathrm{Cu}$ oxides, the formation of various kinds of $\mathrm{Ti}$ oxide would be most preferred with $\mathrm{Cr}$ oxide next. These consideration correspond with the AES depth profile results. In the case of a $\mathrm{Ti}$ interlayer, the oxygen content in the interfacial region was up to 35 at\%. Therefore, in the vicinity of the interface, the deposited layer could be regarded as Ti(ON) rather than TiN. This was confirmed by the Auger fine structure. Fig.6 shows the AES spectra of the Ti $\mathrm{L}_{23} \mathrm{M}_{23} \mathrm{M}_{45}$ peak during the depth profiling. It can be seen that for the $\mathrm{Ti}$ and $\mathrm{Cr}$ interlayers, the binding state of the TiN in the interfacial region is Ti-O,N rather than Ti-N. This is shown by the variation of the position and line shape with the positive excursion of peaks which arises as a result of the influence of a Ti-N cross transition at $413 \mathrm{eV}$ and the binding state. Thus it is considered that oxygen in the interface plays an important role in the adhesion of the deposited layer and the Ti(ON) phase which exists in the interface could enhance the adhesion of $\mathrm{TiN}$ coatings in the case of $\mathrm{Ti}$ and $\mathrm{Cr}$ interlayer formation.

\section{Concluding Remarks}

We have studied the effects of metallic interlayer formation such as the $\mathrm{Ti}, \mathrm{Cr}, \mathrm{Cu}$ on the adhesion of the PACVD-TiN coatings on M2 tool steel.

The experimental results indicate that thin $\mathrm{Ti}$ intermediate layers $(<600 \AA)$ could increase the adhesion and the critical normal force in the scratch adhesion test was up to 60 $\mathrm{N}$. In the case of $\mathrm{Ti}$ interlayer formation, the oxygen in the interfacial region plays an important role in the adhesion of TiN coatings by the formation of a $\mathrm{Ti}(\mathrm{ON})$ phase.

\section{REFERENCES}

11/ U. Helmersson, et al., J. Vac. Sci. Technol., A3(2) (1985) 308

12/ M. Van Stappen, et al., Proc. of 7th Int. Conf. on Ion \& Plasma Assisted Techniques, (1989) 209

13/ J. Valli, et al,, J. Vac. Sci. Technol., A3(6) (1985) 2411

14/ Li Shizhi, et al., Surface \& Coatings Technology, V43/44 (1990) 1007

/5/ D. H. Jang, J. S. Chun and J. G. Kim, Thin Solid Films, V169 (1989) 57

16/ D. H. Jang, J. S. Chun and J. G. Kim, J. Vac. Sci. Technol., A7 (1989) 31

/7/ P. T. Dawson and K. K. Tzatzov, Surface Science, V149 (1985) 105

18/ Smithells Metals Reference Book, 6th ed., edited by E.A.Brandes, Butterworth \& Co. Ltd, (1983) p 14-3 

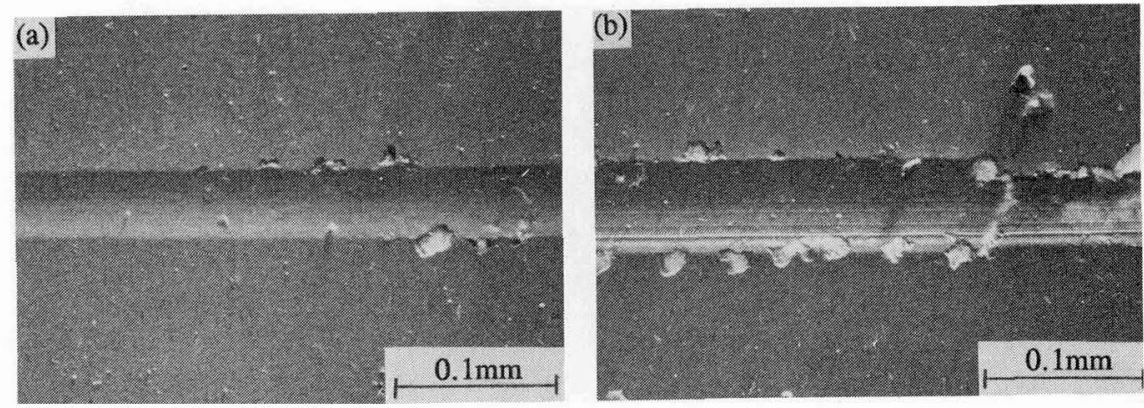

Fig. 1 Typical Scratch Channels

(a) cracking and chipping of TiN coating occurred

(b) detachment and penetration of TiN coating occurred
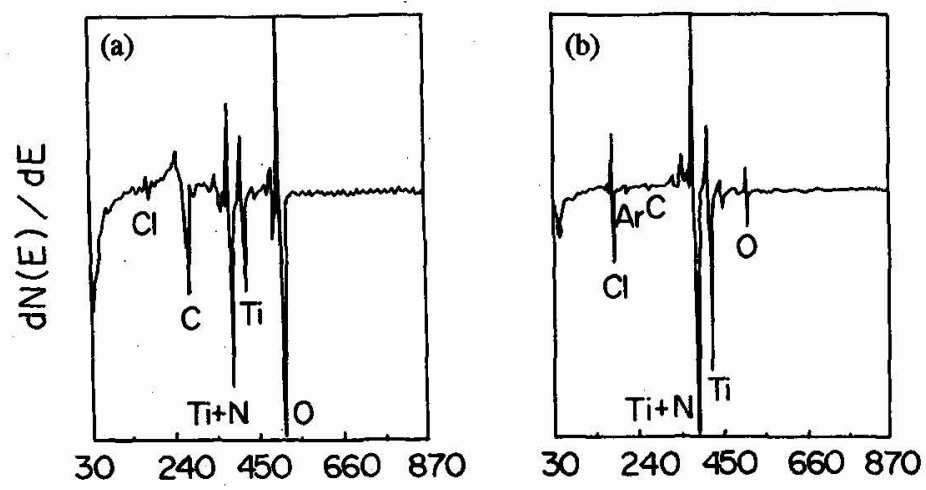

Electron Energy (eV)

Fig. 2 Representative AES spectrum of PACVD - TiN

(a) as received

(b) after 10 min sputter cleaning with $\mathrm{Ar}^{+}$ion beam 


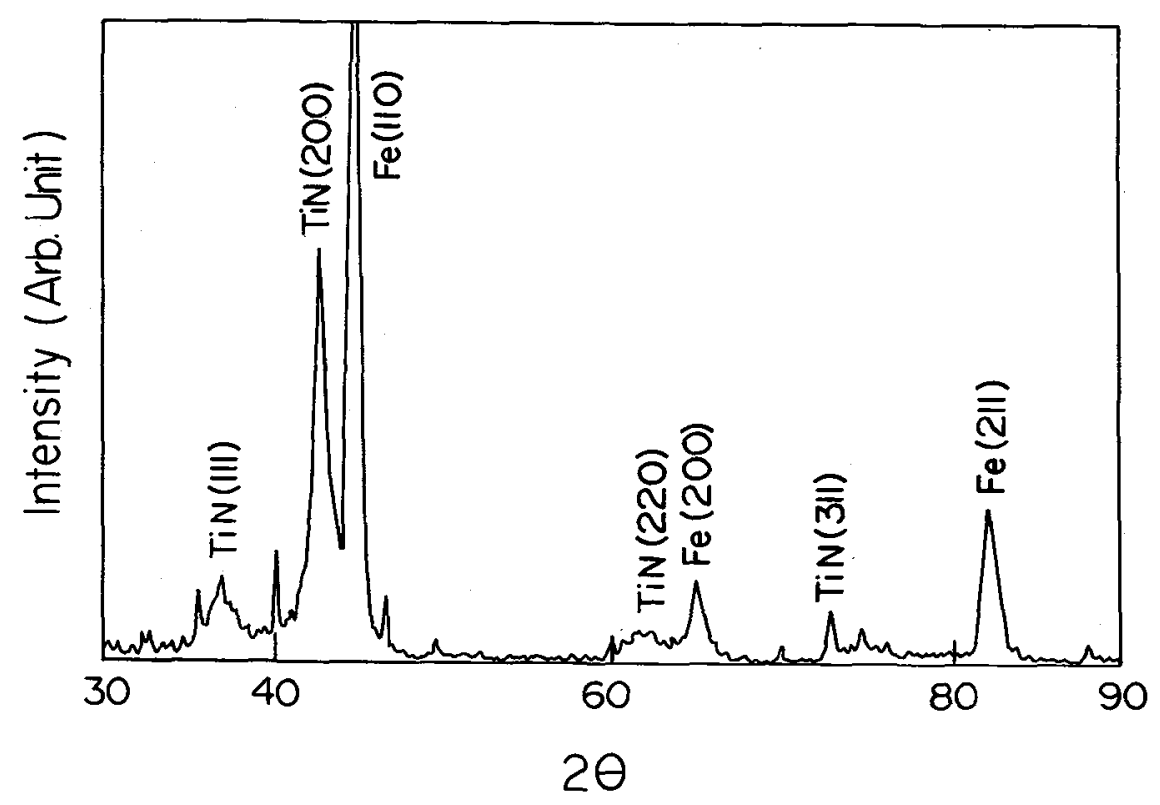

Fig. 3 Typical X-ray diffraction result of PACVD - TiN

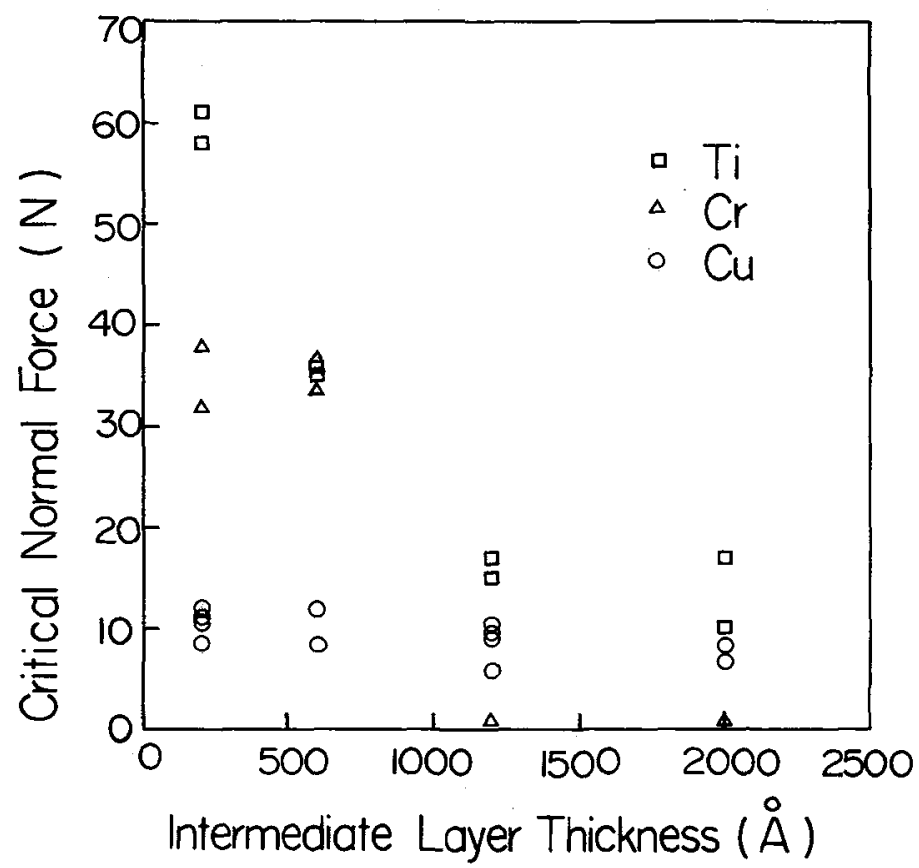

Fig. 4 The effects of the $\mathrm{Ti}, \mathrm{Cr}, \mathrm{Cu}$ interlayer thickness on the adhesion of TiN coatings 


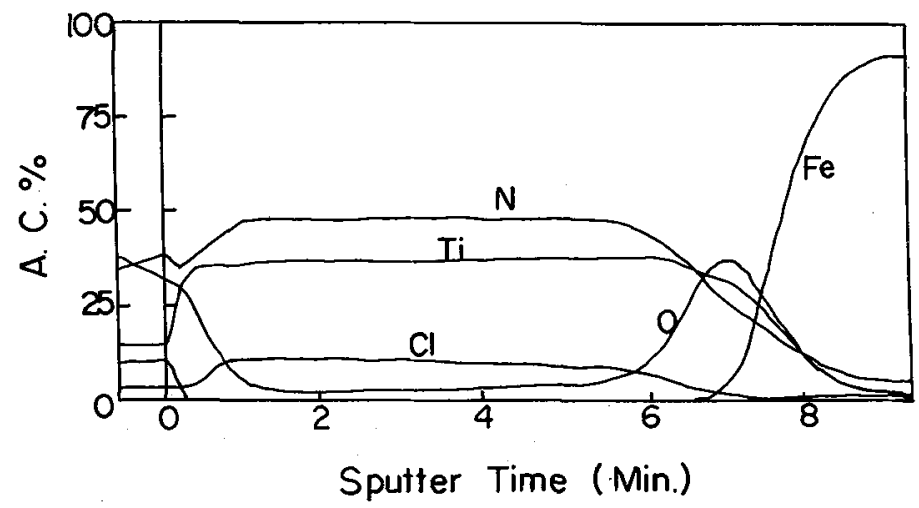

(a)

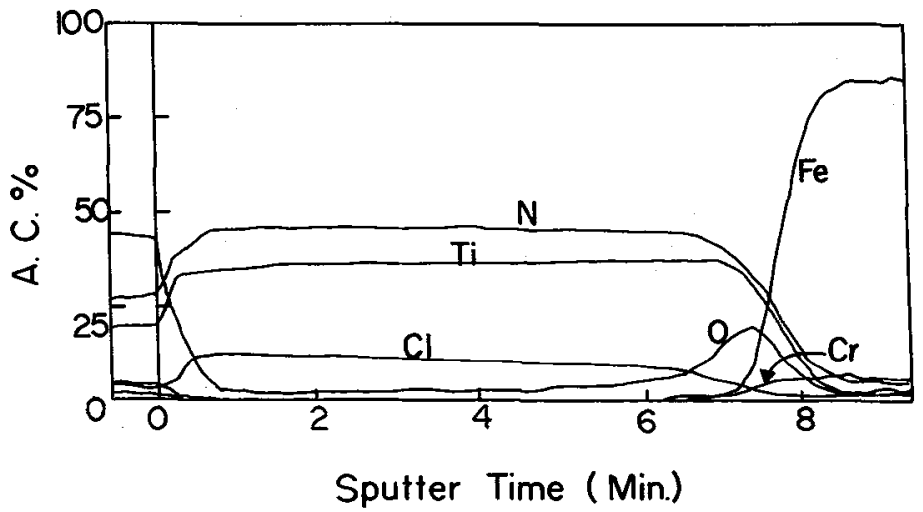

(b)

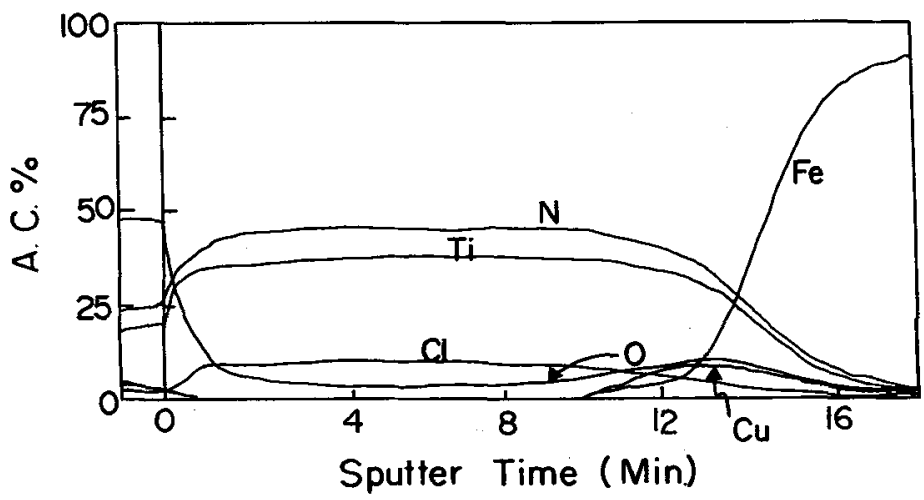

(c)

Fig. 5 AES depth profile results showing the chemical composition of the interfacial region for different interlayers (interlayer thickness, $200 \AA$ ).

(a) for $\mathrm{Ti}$ interlayer, (b) for $\mathrm{Cr}$ interlayer, (c) for $\mathrm{Cu}$ interlayer 


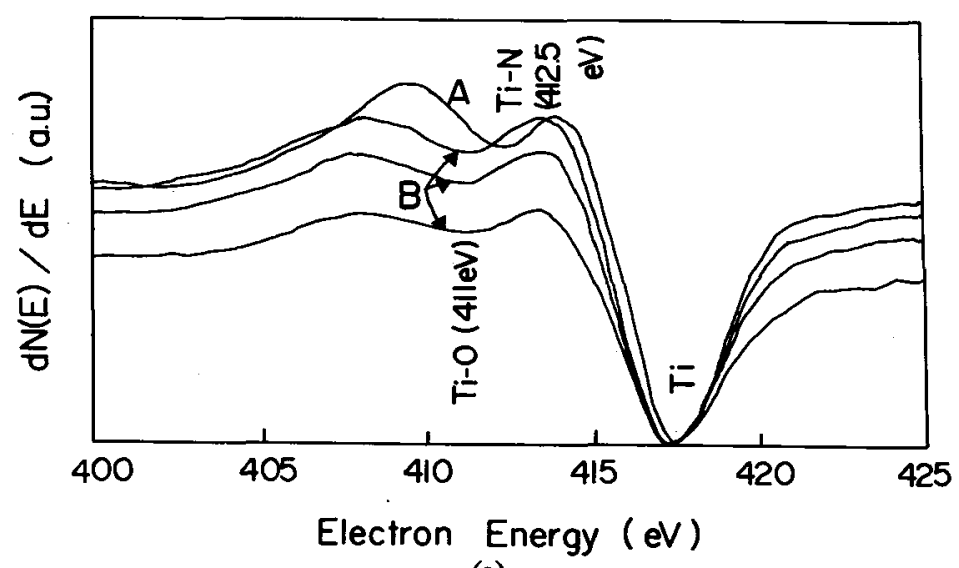

(a)

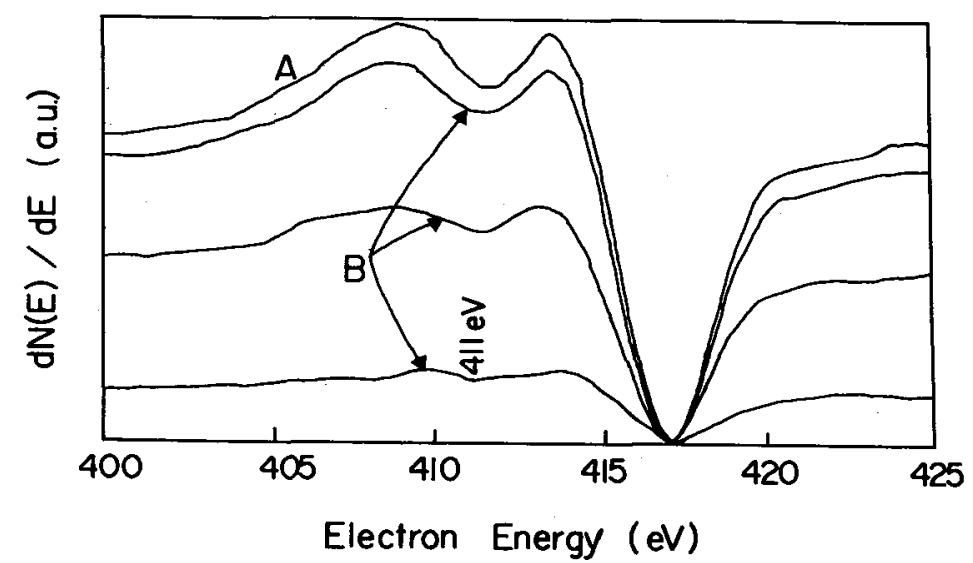

(b)

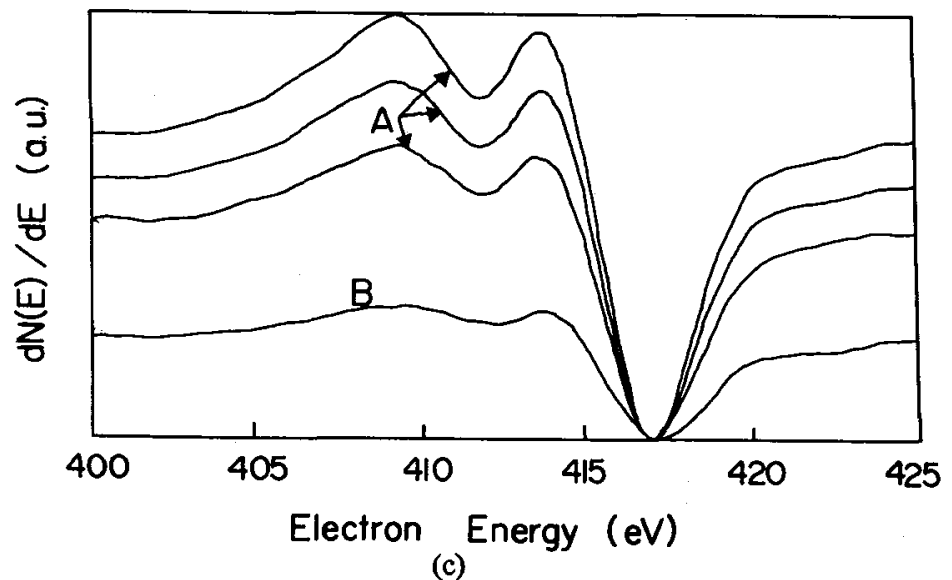

Fig. 6 Ti $\mathrm{L}_{23} \mathrm{M}_{23} \mathrm{M}_{45}$ signals during the depth profiles for different interlayers ( A : for TiN films, B : for interfacial region )

(a) for $\mathrm{Ti}$ interlayer, (b) for $\mathrm{Cr}$ interlayer, (c) for $\mathrm{Cu}$ interlayer 